\title{
EDITORIAL
}

\section{Challenges in solid organ transplantation in people living with HIV}

\author{
Jose M. Miro ${ }^{1 *}$, Paolo A. Grossi ${ }^{2}$ and Christine M. Durand ${ }^{3}$
}

๑ 2019 Springer-Verlag GmbH Germany, part of Springer Nature

Combined antiretroviral therapy (ART) has made HIV infection a manageable chronic disease, allowing a near normal lifespan. Consequently, aging HIV-infected patients face the chronic health conditions and organ failures of the general population. The most important advance in 2 decades is HIV-infected patients with endstage organ disease being evaluated for and undergoing solid organ transplantation (SOT) [1], now routine clinical care in developed countries and increasingly frequent in developing ones. Multidisciplinary teams including HIV specialists are needed to improve outcomes.

So far, we have learned that, first, any organ can be transplanted to HIV-infected patients. Most frequently, it is the kidney, liver and heart, with the pancreas, combined kidney and pancreas and lung transplants also being successful. Second, HIV criteria for SOT have worked [1, 2]. Patients with well-controlled HIV infection on ART, without previous opportunistic infections (OIs) (or with treatable and preventable ones) and meeting minimum $\mathrm{CD} 4+\mathrm{T}$ cell counts $(>100$ for liver and $>200$ for other SOT), do not face higher risks of developing OIs after SOT, and HIV-infection remains well controlled. Furthermore, non-boosted integrase inhibitor (e.g., raltegravir and also dolutegravir and bictegravir, although there is less clinical experience) based ARTs [3] have avoided drug-drug interactions with immunosuppressors (e.g., calcineurin inhibitors) and direct antiviral agents (DAAs) for hepatitis $\mathrm{C}$ virus ( $\mathrm{HCV}$ ), simplifying the treatment and improving the management and possibly the outcome of this challenging population. Third, dialysis should only be a bridge to kidney transplantation.

*Correspondence: jmmiro@ub.edu

${ }^{1}$ Infectious Diseases Service, Hospital Clinic - IDIBAPS, University of Barcelona, Villarroel, 170, 08036 Barcelona, Spain

Full author information is available at the end of the article
It has shown its safety and a better prognosis and quality of life for HIV-infected individuals than continued hemodialysis [4]. Fourth, liver transplantation (LT) is a safe and effective therapy for selected HIV-infected patients with hepatocellular carcinoma (HCC) [5], a leading non-AIDS defining cancer in this population. Fifth, acute rejection is more common in SOT HIV-infected recipients and associated with graft loss [6-8]. The pathophysiology is unknown, and transplant teams must diagnose and treat early. Finally, mid- ( 5 years) and long-term (10 years) survival rates of kidney, liver and heart transplantation are lower than their matched HIV-negative recipients but are still acceptable (Table 1) (see references in supplementary material). HCV co-infection has negatively affected these results, as the cure rate with pegylated interferon and ribavirin was low. However, interferon-free DAAs have since changed this, and cure rates for LT are high, similar to those in HIV-negative recipients [9]. With HCV eliminated, the prognosis of liver and renal transplantation in HIV-infected patients is good (Table 1). Eliminating $\mathrm{HCV}$ is important in liver retransplantation, as the outcomes of HCV-HIV co-infected recipients are poor short term [10].

Many challenges remain, however, particularly combined organ transplantation and small donor organ pools for HIV- and non-HIV-infected patients. Combined kidney-liver transplantation (CKLT) and simultaneous kidney-pancreas transplantation (SKPT) have been reported in HIV-infected patients with contradictory results. The NIH trial [7] of LT in HIV-infected individuals showed CKLT to be associated with poor outcomes. It has therefore been rarely performed with these results negatively impacting decisions by transplant teams. We believe that it should be revisited in the current era. Experience in SKPT in HIV-infected individuals is still limited. A few case reports suggest that it is feasible in individuals with HIV, although outcomes are mixed. In the largest series

\section{Springer}


Table 1 Long-term survival of kidney, liver and heart transplants in HIV-infected recipients compared with HIV-negative controls

\begin{tabular}{|c|c|c|c|c|c|c|c|c|c|}
\hline \multirow{2}{*}{$\begin{array}{l}\text { Type of SOT/country } \\
\text { (references) }\end{array}$} & \multirow[t]{2}{*}{ Period } & \multirow[t]{2}{*}{ Number of patients } & \multicolumn{6}{|l|}{ Years } & \multirow[t]{2}{*}{$P$ value } \\
\hline & & & 1 & 2 & 3 & 4 & 5 & 10 & \\
\hline \multirow[t]{2}{*}{ Kidney/USA [1] } & $2002-2011$ & $\mathrm{HIV}+\mathrm{HCV}-(n=362)$ & $96 \%$ & - & $92 \%$ & - & $89 \%$ & $64 \%$ & 0.096 \\
\hline & & HIV $-\mathrm{HCV}-(n=3620)$ & $97 \%$ & - & $94 \%$ & - & $89 \%$ & $78 \%$ & \\
\hline \multirow[t]{2}{*}{ Kidney/USA [1] } & 2002-2011 & $\mathrm{HIV}+\mathrm{HCV}+(n=104)$ & $91 \%$ & - & $77 \%$ & - & $67 \%$ & $29 \%$ & 0.001 \\
\hline & & HIV $-\mathrm{HCV}+(n=1050)$ & $94 \%$ & - & $86 \%$ & - & $79 \%$ & $56 \%$ & \\
\hline \multirow[t]{2}{*}{ Liver/Spain [2] } & $2002-2006$ & $\mathrm{HIV}+/ \mathrm{HCV}+(n=84)$ & $88 \%$ & $71 \%$ & $62 \%$ & $60 \%$ & $54 \%$ & - & 0.008 \\
\hline & & $\mathrm{HIV}-/ \mathrm{HCV}+(n=252)$ & $90 \%$ & $81 \%$ & $76 \%$ & $73 \%$ & $71 \%$ & - & \\
\hline \multirow[t]{2}{*}{ Liver/Spain [3] } & 2002-2009 & $\mathrm{HIV}+/ \mathrm{HCV}+\mathrm{SVR}(n=16)$ & $93 \%$ & $87 \%$ & $79 \%$ & $79 \%$ & $79 \%$ & - & 0.093 \\
\hline & & $\mathrm{HIV}-/ \mathrm{HCV}+\mathrm{SVR}(n=64)$ & $98 \%$ & $98 \%$ & $98 \%$ & $92 \%$ & $92 \%$ & - & \\
\hline \multirow[t]{2}{*}{ Liver/USA [4] } & 2002-2011 & $\mathrm{HIV}+/ \mathrm{HCV}+(n=117)$ & $77 \%$ & - & $59 \%$ & - & $52 \%$ & $44 \%$ & $<0.001$ \\
\hline & & $\mathrm{HIV}-/ \mathrm{HCV}+(n=15,581)$ & $88 \%$ & - & $76 \%$ & - & $69 \%$ & $60 \%$ & \\
\hline \multirow[t]{2}{*}{ Liver/USA [5] } & $2001-2007$ & $\mathrm{HIV}+/ \mathrm{HBV}+(n=22)$ & $85 \%$ & - & $85 \%$ & - & $85 \%$ & - & 0.090 \\
\hline & & HIV $-/$ HBV $+(n=20)$ & $100 \%$ & - & $100 \%$ & - & $100 \%$ & - & \\
\hline \multirow[t]{2}{*}{ Heart/USA [6] } & 1999-2004 & $\mathrm{HIV}+(n=20)$ & $86 \%$ & - & $79 \%$ & - & - & - & 0.950 \\
\hline & & $\mathrm{HIV}-(n=9174)$ & $90 \%$ & - & $90 \%$ & - & - & - & \\
\hline \multirow[t]{2}{*}{ Heart/USA [7] } & 2004-2016 & $\mathrm{HIV}+(n=35)$ & $100 \%$ & - & $88 \%$ & - & $88 \%$ & - & 0.149 \\
\hline & & HIV $-(n=21,400)$ & $89 \%$ & - & $83 \%$ & - & $77 \%$ & - & \\
\hline
\end{tabular}

References are listed in the supplementary material

SVR sustained virologic response

[11] of four HIV-infected recipients with type 1 diabetes mellitus and end-stage renal disease (ESRD), all patients suffered complications requiring surgical re-exploration and postoperative infections. At a mean follow-up of 45 months, all four had normal renal function, and one experienced late pancreatic graft failure, whereas three remained insulin independent. More data are needed to determine if pancreas transplantation in HIV-infected recipients is safe and feasible.

Unfortunately, donor organs are in short supply, whereas waiting lists grow. Using organs from living donors is not well explored in HIV-infected patients, and using organs from $\mathrm{HCV}$-infected or HIV-infected donors is currently being investigated. Living-donor kidney transplantation (KT) is the oldest solid organ transplantation and is associated with better outcome than deceased-donor KT in the general population. However, in a recent publication [12], the likelihood of livingdonor KT in HIV-infected candidates has been reported to be $47 \%$ lower, with a trend toward lower likelihood of deceased-donor KT. However, in the NIH trial [6] of KT in HIV-infected individuals, using living-donor transplants was protective against graft loss. Therefore, HIVinfected patients with ESRD should not be excluded from living-donor transplant programs. Living-donor liver transplantation (LDLT) has been controversial since its inception because of the significant risks to the living donor, including death and substantial morbidity. For these reasons and because of the initial poor outcomes of LT in $\mathrm{HIV} / \mathrm{HCV}$ co-infected patients in the pre-DAA era, LDLT in HIV-infected individuals has not been considered so far. We believe that in the current era of ART and DAAs, it should be explored as an alternative to deceased-donor transplantation.

The use of deceased $\mathrm{HCV}+$ donors for $\mathrm{HCV} / \mathrm{HIV}$ coinfected recipients showed inferior results in the $\mathrm{NIH}$ trial [7] of LT in HIV-infected individuals. However, it should be reassessed in the future in both LT and KT in HIV-infected recipients because of the good preliminary results in $\mathrm{KT}$ in HIV-uninfected individuals, where pre- and post-transplant HCV treatment with DAAs was safe and prevented chronic $\mathrm{HCV}$ infection in $\mathrm{HCV} \mathrm{D}+1$ $\mathrm{R}$ - kidney transplant recipients [13]. Another emerging research field is the transplantation of organs from HIV-infected donors to HIV-infected recipients (HIV $\mathrm{D}+/ \mathrm{R}+)$. There are unique risks of HIV $\mathrm{D}+/ \mathrm{R}+$ transplant to consider [1]. These include donor-to-recipient HIV superinfection, occult OIs in HIV-infected donors or lower organ quality due to the impact of chronic HIV on organ function. These theoretical risks will need to be weighed against the morbidity and mortality of remaining on waiting lists and the survival benefit of transplantation. The practice of HIV D+/R+ KT was pioneered in South Africa by Muller et al. [14] who reported 3- and 5 -year patient survival of $84 \%$ and $74 \%$, respectively, for 27 HIV D+/R+ kidney transplants. These outcomes are 
not significantly different from outcomes of HIV+ kidney transplants using HIV-uninfected donors (HIV D-/ $\mathrm{R}+$ ). Furthermore, this series saw neither HIV virologic failure nor AIDS-defining OIs. HIV $\mathrm{D}+/ \mathrm{R}+$ liver transplant experience is limited to a few case reports without unusual complications. In the USA, federal law banned HIV D+/R+ transplantation in 1984, but it was revised with the HIV Organ Policy Equity (HOPE) Act in 2013, allowing HIV D+/R+ transplants in research trials. Multicenter national trials investigating the practice of HIV $\mathrm{D}+/ \mathrm{R}+$ deceased-donor kidney and liver transplantation (NCT02602262, NCT03500315) and HIV D+/R+ living donor kidney transplantation (NCT03408106) are underway.

In conclusion, the field of SOT in HIV-infected patients is evolving rapidly. As a recent example, a publication reporting the successful LDLT from an HIV-positive to an HIV-negative individual opens a completely new scenario in the setting of SOT in HIV-infected individuals [15].

\section{Electronic supplementary material}

The online version of this article (https://doi.org/10.1007/s00134-019-05524-1) contains supplementary material, which is available to authorized users.

\section{Author details \\ ${ }^{1}$ Infectious Diseases Service, Hospital Clinic - IDIBAPS, University of Barcelona, Villarroel, 170, 08036 Barcelona, Spain. ${ }^{2}$ Infectious and Tropical Diseases Unit, Department of Medicine and Surgery, University of Insubria, Varese, Italy. ${ }^{3}$ Department of Medicine, Johns Hopkins University School of Medicine, Baltimore, MD, USA.}

\section{Acknowledgements}

JMM received a personal 80:20 research Grant from the Institut $d^{\prime}$ Investigacions Biomèdiques August Pi i Sunyer (IDIBAPS), Barcelona, Spain, during 2017-2019.

\section{Funding}

JMM has received consulting honoraria and/or research grants from AbbVie, Angelini, Contrafect, Cubist, Genentech, Gilead Sciences, Jansen, Medtronic, MSD, Novartis, Pfizer and ViiV Healthcare; PAG has received consulting honoraria and/or research grants from Angelini, BD, Biotest, Gilead, MSD, Nordic, Paratek, Pfizer and Shire. CMD has received consulting honoraria and/or research grants from Bristol Meyers Squibb, Gilead Sciences, GlaxoSmithKline, Merck Dome \& Corp. and ViiV Healthcare.

\section{Publisher's Note}

Springer Nature remains neutral with regard to jurisdictional claims in published maps and institutional affiliations.
Received: 26 November 2018 Accepted: 6 January 2019

Published online: 14 January 2019

\section{References}

1. Shaffer AA, Durand CM (2018) Solid organ transplantation for HIVinfected individuals. Curr Treat Options Infect Dis 10:107-120

2. Miro JM, Torre-Cisnero J, Moreno A et al (2005) GESIDA/GESITRA-SEIMC, PNS and ONT consensus document on solid organ transplant (SOT) in HIV-infected patients in Spain (March, 2005). Enferm Infecc Microbiol Clin 23:353-362

3. Tricot L, Teicher E, Peytavin G et al (2009) Safety and efficacy of raltegravir in HIV-infected transplant patients cotreated with immunosuppressive drugs. Am J Transplant 9:1946-1952

4. Locke JE, Gustafson S, Mehta S et al (2017) Survival benefit of kidney transplantation in HIV-infected patients. Ann Surg 265:604-608

5. Agüero F, Forner A, Manzardo C et al (2016) Human immunodeficiency virus infection does not worsen prognosis of liver transplantation for hepatocellular carcinoma. Hepatology 63:488-498

6. Stock PG, Barin B, Murphy B et al (2010) Outcomes of kidney transplantation in HIV-infected recipients. N Engl J Med 363:2004-2014

7. Terrault NA, Roland ME, Schiano T et al (2012) Outcomes of liver transplant recipients with hepatitis $C$ and HIV coinfection. Liver Transpl 18:716-726

8. Miro JM, Montejo M, Castells L et al (2012) Outcome of HCV/HIV-coinfected liver transplant recipients: a prospective and multicenter cohort study. Am J Transplant 12:1866-1876

9. Manzardo C, Londoño MC, Castells L et al (2018) Direct-acting antivirals are effective and safe in $\mathrm{HCV} / \mathrm{HIV}$-coinfected liver transplant recipients who experience recurrence of hepatitis $C$ : a prospective nationwide cohort study. Am J Transplant 18:2513-2522

10. Agüero F, Rimola A, Stock P et al (2016) Liver retransplantation in patients with HIV-1 infection: an international multicenter cohort study. Am J Transplant 16:679-687

11. Grossi PA, Righi E, Gasperina DD et al (2012) Report of four simultaneous pancreas-kidney transplants in HIV-positive recipients with favorable outcomes. Am J Transplant 12:1039-1045

12. Locke JE, Mehta S, Sawinski D et al (2017) Access to kidney transplantation among HIV-infected waitlist candidates. Clin J Am Soc Nephrol 12:467-475

13. Durand CM, Bowring MG, Brown DM et al (2018) Direct-acting antiviral prophylaxis in kidney transplantation from hepatitis $C$ virus-infected donors to noninfected recipients: an open-label nonrandomized trial. Ann Intern Med 168:533-540

14. Muller E, Barday Z, Mendelson M, Kahn D (2015) HIV-positive-to-HIVpositive kidney transplantation - results at 3-5 years. N Engl J Med 372:613-620

15. Botha J, Conradie F, Etheredge $\mathrm{H}$ et al (2018) Living donor liver transplant from an HIV-positive mother to her HIV-negative child: opening up new therapeutic options. AIDS 32:F13-F19 